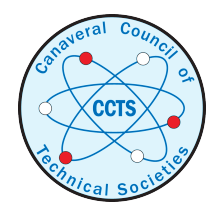

Mar 7th, 8:00 AM

\title{
The Origin of Meteorites: Space Erosion and Cosmic Radiation Ages
}

David E. Fisher

Nuclear Reactor Laboratory and Center for Radiophysics and Space Research - Cornell University

Follow this and additional works at: https://commons.erau.edu/space-congress-proceedings

\section{Scholarly Commons Citation}

Fisher, David E., "The Origin of Meteorites: Space Erosion and Cosmic Radiation Ages" (1966). The Space Congress ${ }^{\circledR}$ Proceedings. 3.

https://commons.erau.edu/space-congress-proceedings/proceedings-1966-3rd/session-2/3

This Event is brought to you for free and open access by the Conferences at Scholarly Commons. It has been accepted for inclusion in The Space Congress ${ }^{\circledR}$

Proceedings by an authorized administrator of Scholarly Commons. For more information, please contact commons@erau.edu.

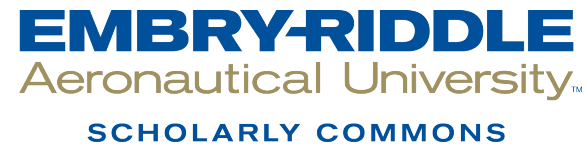


David E. Fisher

Nuclear Reactor Laboratory and

Center for Radiophysics and Space Research

Comell University, Ithaca, New York

\section{Summary}

A reasonable amount of space erosion, due to dust particles in the asteroidal belt, coupled with the fact that there is a high mass cut-off for chondrites at about $1000 \mathrm{~kg}$, is sufficient to explain the absence of chondrites with radiation ages greater than $55 \times 10^{6}$ years. Then if one postulates continuous creation of meteorites by asteroidal collisions, the effect of space erosion is to shift the measured ages toward lower values and to destroy a certain portion of meteorites as a function of their time in space. The total effect, as estimated with several simple but plausible erosion rates, is to duplicate quite nicely the observed shape of the radiation age spectrum. Thus space erosion is not the sole factor in determining the radiation age of a chondrite, but is a factor which grows in importance as the age increases, becoming the sole factor at $55 \times 10^{6}$ years. The model is in agreement with the postulate of a distinct bronzite producing collision 4 million years ago, whose effect is observed on top of the background of continuous collision. It is therefore suggested that both stone and iron meteorites are created by collisional processes in the asteroidal belt.

\section{Introduction}

The question of place of origin of the meteorites has not yet been satisfactorily resolved. Two possible sources are immediately obvious: the asteroidal belt and the surface of the moon. The experimental data which are most pertinent to this question are the measured cosmic radiation ages of the meteorites, which date the time between their reduction to metersized bodies (presumably through some collisional break-up) and their capture by the earth. The main characteristic of these ages is that the iron meteorites have ages on the order of $10^{8}-10^{9}$ years, while the stones have ages of from $2-50 \times 10^{6}$ years. There may be a fine structure in the age spectrum, with irons clustered at $6 \times 10^{8}$ years and stones at $5 \times 10^{6}$ years, but this paper will be concerned primarily with the overall character of the meteoritic age diagram, as shown in Figure 1. The interpretation of age clusters will be discussed as a perturbation on the overall scheme.

The discrepancy between the iron and stone ages (we restrict ourselves now to chondritic stones, for which a statistically significant number of radiation ages have been measured) has been accounted for by Urey ${ }^{1}$ on the basis that the irons come to us from the asteroidal belt, and the stones from the surface of the moon.
This derives from Opik's ${ }^{2}$ calculation of $10^{8}-10^{9}$ years as the collision lifetime of objects coming from the asteroidal belt, and $10^{7}$ years for objects coming from the moon. Many of the objections to a lunar origin were based on mechanical difficulties, which might be removed by the postulate of cometary impacts. And Arnold ${ }^{3}$ indicates that a lunar origin is possible if most of the chondrites originated in a few large events occurring more than $10^{6}$ years ago. But recent work by Hapke 4,5 seems to demonstrate conclusively that the photometric properties of the moon are not compatible with those of chondrites.

The asteroidal belt, on the other hand, would seem at first glance to a perfectly suitable place from which all the meteorites might come. The size and relative velocity of the asteroids indicate that asteroidal collisions must be commonplace phenomena; in fact, calculations by Kuiper ${ }^{6}$ indicate that catastrophic collisions should occur at intervals of $10^{4}-10^{5}$ years, that is, on a cosmic time scale, vintually continuously. The radiation ages of the irons are perfectly reconciliable with an asteroidal origin, as Indicated above, but the ages of the chondrites have led various authors to the conclusion that a separate origin, or a more complicated history, is indicated for these objects. Thus, Anders 7 says that "The hypothesis of continuous meteorite production by asteroidal collisions would therefore be perfectly acceptable, were it not for the curious systematic difference between the exposure ages of stones and irons." And Annold ${ }^{3}$ concludes that the asteroidal density appears to be insufficient to be consistent with the cross section for destruction by asteroidal collision required to account for the chondritic ages: "This is a strong argument against an asteroidal origin for chondrites, unless another unknown mechanism exists for shortening chondrite ages."

It is the purpose of this paper to suggest that space erosion may be this "unknown mechanism".

\section{Cosmic Radiation Ages}

Since the object of this paper is to duplicate the cosmic radiation age spectrum of the chondrites by a calculation based on space erosion, it is necessary to review and evaluate the measured cosmic radiation ages. Only a very few ages have been determined by actual measurements of both a radioactive and a stable cosmogenic nuclide, too few to accept as describing any general trend in the ages. 
Instead, one is forced to rely on ages estimated from actual $\mathrm{He}^{3}$ (and sometimes $\mathrm{Ne}^{21}$ and $\mathrm{Ar}^{38}$ ) measurements, and an averaged $\mathrm{H}^{3}$ production rate. This procedure generally is justified by the statement that the measured $\mathrm{H}^{3}$ activities do not show much variation from one meteorite to another. In actual fact, they vary from $0.1-0.8 \mathrm{dpm} / \mathrm{g}^{8}$. A comparison of the ages of those meteorites for which actual $\mathrm{He}^{3} / \mathrm{H}^{3}$ measurements have been carried out with the ages one would estimate for them by the $\mathrm{He}^{3}$ data alone is shown in Table 1 . The errors in the ages based on $\mathrm{He}^{3}$ data alone are sometimes claimed to be on the onder of $\pm 20 \%$, and on this basis anguments based on possible fine structure in the age diagram are made. It would appear from Table 1 , however, that errors of a factor of two must be common. This, together with the statistically insufficient number of analyses for most meteoritic classes, make discussion of the fine structure premature. For only three classes of chondrites are there a reasonable number of analyses: the amphoteric chondrites ${ }^{9}$, the bronzite chondrites, and the hypersthene chondrites 10. Of these, only the bronzites show real evidence of an age cluster. We will discuss, therefore, the overall age spectrum of Fig. 1, and then, in a separate section, examine the meaning of the bronzite cluster.

\section{The Previous Space Erosion Model}

The idea of space erosion as the dominant factor in the radiation ages of the stones and irons has been put forward by Fireman and DeFelice ${ }^{16}$, but has been severely criticized, and rejected by Anders 7, Eberhardt and Geiss 17 and others. The criticisms, which will be discussed in detail later with respect to their applicability to the model proposed here, were all based on the following model proposed by Whipple and Fireman 18 :

Cosmogenic production of a nuclide $\mathrm{X}$ follows the equation

$$
\mathrm{dx} / \mathrm{dt}=A \mathrm{e}^{-\mathrm{aR}}
$$

where $a$ and $A$ are constants, and where $R$ is the distance between the sample and the surface of the meteorite. The total content of a cosmogenic stable nuclide is then

$$
(x)=A \int_{0}^{T^{t}} e^{-a(r+E t)} d t
$$

where $r$ is the preatmospheric radius of the meteorite, $\mathrm{E}$ is the erosion rate, and $\mathrm{T}^{\prime}$ is the true radiation exposure age of the meteorite. The measured production rate, which is measured at time of fall of the meteorite, is not Eq. (1) but is

$$
(d x / d t)=A e^{-a r}
$$

and the measured radiation age $T$ is therefore

$$
\begin{aligned}
T & =(X) / A e^{-a r} \\
& =\frac{1-e^{-a E T^{\prime}}}{a E}
\end{aligned}
$$

Then, as the true radiation age $T^{\prime}$ becomes very large compared to $\mathrm{T}$, the erosion rate reaches a maximum value

$$
\mathrm{E}=(\mathrm{aT})^{-1}
$$

This analysis was presented by Whipple and Fireman as a means of estimating the maximum possible erosion rate of iron meteorites. Subsequently it has been discussed as the means by which the measured radiation ages of the stones have been shortened. That is, that the measured ages of the stones are not determined by Eq. (4) but by

$$
T=(a E)^{-1}
$$

It was therefore concluded that, to a first approximation, the ages of all chondrites should be the same, or, to a second approximation, that the ages should vary according to varying erosion rates which would be dependent on the brittleness of the individual meteorites. These conclusions are not in accord with the observed facts.

\section{The Proposed Model}

The model presented in this paper does not propose that space erosion alone is responsible for the measured radiation ages, as per Eq. (7), but suggests that space erosion may be a contributing factor, as per Eq. (5). The model is based on the following assumptions:

1. The iron meteorites were formed at times indicated by their cosmic radiation ages, or at times previous to these, by collision of larger bodies in the asteroidal belt. They have suffered negligible space erosion compared to that suffered by the stone meteorites. This question will be discussed later, following Eq. (il). For now, we simply point out that the Fireman-Whipple Eq. (6) can be used to determine the maximum amount of space erosion that might have taken place. This was done in an earlier paper ${ }^{19}$; the result, corrected for a more precisely determined age of the Grant meteorite, is $\mathrm{E}_{\max } \sim_{3.7} \times 10^{-8}$ $\mathrm{cm} / \mathrm{yr}$.

2. The stone meteorites are being formed continuously by collisions in the asteroidal belt. Continuous formation of stone meteorites, as opposed to the episodic formation of iron meteorites, implies that the greatest number density of asteroids correponds to stony meteoritic material. 
3. The mass-number density distribution of meteorites, as created in the asteroidal belt, follows an exponential form, as discussed by Arnold ${ }^{3}$ or Brown ${ }^{20}$. But this distribution on earth, that is, the mass-number density distribution of meteorites whose ages have been measured and which therefore form the data which are to be explained, differs from the exponential form. At masses lower than about $30 \mathrm{~kg}$. the numbers begin to drop off, and there are no stone meteorites measured with a mass greater than $900 \mathrm{~kg}$.; indeed the langest known stone weighs $1024 \mathrm{~kg}$. It is improbable that this cut-off is due solely to chance. Rather, it is likely due to a finite escape velocity from the colliding bodies ${ }^{3}$, and therefore represents a real limit to the maximum possible size of chondrites. Thus it seems most reasonable to base the argument on the actual mass distribution of meteorites whose ages have been measured. This is given in Fig. 2.

We picture, then, that in each unit interval of time, beginning at a time comparable to the age of the iron meteorites or previous, stone meteorites are being formed, falling to earth, and being collected and measured in the number-mass relationship given in Fig. 2. It follows that an effective erosion rate equal to or greater than that given by

$$
E_{\min }=r_{\max } / T^{\prime} \max
$$

where $r_{\max }$ is the maximum radius, corresponding to a $10^{3}-\mathrm{kg}$ chondrite, and $\mathrm{T}^{\prime} \max$ is the true radiation age of the oldest chondrite, is sufficient to account for the fact that no chondrites exist whose measured age is larger than about $55 \times 10^{6}$ years. This value of $E_{\text {min }}$ can be estimated from the relationship

$$
T_{\max }=55 \times 10^{6}=\left(1-e^{-a E \min T^{\prime} \max }\right) / a E_{\text {min }}
$$

Taking $a=1 / 45 \mathrm{~cm}^{-1}, E_{\min } T^{\prime} \max =r_{\max }$, and $r_{\max }$ equal to twice the postatmospheric radius of the $10^{3}-\mathrm{kg}$ (to allow for atmospheric ablation),

$$
E_{\min }=\frac{1-e^{-a r_{\max }}}{a T_{\max }}=0.56 \times 10^{-6} \mathrm{~cm} / \mathrm{yr}
$$

One can make a very rough independent approximation of the erosion rates to be expected in space. The orbital inclinations and eccentricities of the asteroids indicate collision velocities $\mathrm{v}$ on the order of $5 \mathrm{~km} / \mathrm{sec}$; the dustasteroidal $\bar{r}$ lative velocities should be about the same. The dust density $\mathrm{P}$ is $p^{\text {robably not }}$ known to better than $10^{-20}-10^{-23} \mathrm{gm} / \mathrm{cm}^{-3}$; we known to better here van de Hulst's $\mathrm{s}^{21}$ estimate of $0.5 \times 10^{-20}$. According to Opik's model22, the ratio of mass ejected to impacting mass is $4.5 \mathrm{v} / \sqrt{s / p}$ where $s$ is the crushing strength and $\underline{\rho}$ is the density of the target. Then the erosion rate would be

$$
\begin{aligned}
E & =4.5 P \nabla^{2} / \sqrt{\mathrm{s} / \rho} \\
& \approx 2 \times 10^{-4} \mathrm{~cm} / \mathrm{yr}
\end{aligned}
$$

for the spherical chondrites, using a value ${ }^{16}$ for the crushing strength of $3 \times 10^{6}$ dynes $/ \mathrm{cm}^{2}$. However, the low crushing strength of these meteorites is due to the softness of the matrix between the chondrules, and Geiss and Oeschger 23 have pointed out that micron-sized dust particles will see, not the matrix as a whole, but individual chondrules, silicate fragments, or pieces of metal. Therefore the use of Eq. (11) is not valid for particles much smaller than the dimensions of individual pieces in the chondrites, which are generally on the order of millimeters. Eq. (11) may be corrected for this effect, in an approximation probably as good as Eq. (11) itself is, as follows: Taking the mass distribution of the asteroidal dust as

$$
\underline{\mathrm{dn} / \mathrm{dlnm}}=\mathrm{km}^{-\mathrm{a}}
$$

by extrapolation of Arnold's ${ }^{3}$ distributuion, with $a=0.76$, and a low-mass cut-off 24 at a dust diameter of about $10^{-3} \mathrm{~cm}$, it is estimated that the ratio of particles with radius in the range 0.1 - 10 millimeters is about $1 / 40$ of the total density. This is the density that may be used in Eq. (11), giving an estimated erosion rate of about $5 \times 10^{-6} \mathrm{~cm} / \mathrm{yr}$. Calculations based on Pietrowski's ${ }^{25}$ model of collisions give an erosion rate about an order of magnitude higher.

For iron meteorites there is no soft matrix to enhance erosion, and the smaller-sized dust particles will be as effective as the larger. Using $\mathrm{Eq}$. (11), with a crushing strength 26 of $3 \times 10^{9}$ dynes $/ \mathrm{cm}^{2}$ and utilizing the full dust density, the erosion rate is calculated to be about $10^{-8} \mathrm{~cm} / \mathrm{yr}$.

These calculations are no better than orderof magnitude estimates. They show merely that: (1) The erosion rate of $0.56 \times 10^{-6} \mathrm{~cm} / \mathrm{yr}$, as per Eq. (10), which is necessary to account for the observed fact that no chondrite has a measured radiation age of greater than $55 \times 10^{6}$ years, is not unreasonably high, and (2) It does not seem unreasonable to postulate that the iron meteorites have undergone an amount of space erosion which is negligible compared to that suffered by the stones.

Now with an erosion rate equal to or greater than $0.56 \times 10^{-6} \mathrm{~cm} / \mathrm{yr}$, and a maximum chondritic radius of $52 \mathrm{~cm}$, it follows that no chondrite will have a measured radiation age greater than $55 \times 10^{6}$ years. The relative numbers of meteorites expected in each 5 million year interval of measured radiation ages from 0 to 55 million years are simply those with a radius greater than the dimensions eroded within the true time aprmesponding to the radiation age. These can be calculated from the mass distribution of Fig. 2, 
for $r=E T^{\prime}$. It is not assumed that $T^{\prime}$ is very much greater than $T$; rather, $T^{\prime}$ is calculated for each $\mathrm{T}$ by $\mathrm{Eq}$. (5). Thus, of all meteorites created longer ago than $\mathrm{T}$ ' and therefore showing a measured radiation age greater than $T$, only those with an initial radius greater than $r=E^{\prime}$ will have escaped total destruction by space erosion and therefore be available to capture by earth. That is, the fraction of meteorites lying in a time interval $\Delta \mathrm{T}$ is given by

$$
N(\Delta T)=\frac{N_{i}(>r)}{\sum_{i N_{i}}}
$$

where $x$ ranges from 0 to $52 \mathrm{~cm}$. A histogram of calculated versus measured ages is shown in Fig. 3. The agreement with the shape of the age spectrum is quite reasonable.

The measured ages are not sufficiently accurate to justify an attempt to fit the calculations to the data by varying parameters and thus to calculate by this model an effective erosion rate. However, it should be instructive to investigate the effect of a few other erosion models:

(1) The origin of the interplanetary dust is not yet settled. If it arises as collisional debris in the asteroidal belt, and if collisions are increasing with time (due to an increasing number of smaller bodies as an effect of the collisions) faster than the dust particles are removed by the Poynting-Robertson effect, then space erosion will not be constant but will be an increasing function of time. Alternatively, the dust density might be a constant of time, but increasing frequency of collisions might modify our assumption (2) towards a frequency of meteorite production increasing with time. To compensate for either of these effects the previous calculation can be done with an erosion rate taken as

$$
E(t)=E_{0} e^{-b t}
$$

where $E_{0}$ is the present erosion rate, $\underline{b}$ is an adjustable parameter, and $t$ is measured backwards from the present. Choosing a value of
$\mathrm{b}=3 \times 10^{-8} \mathrm{yr}^{-1}$, with $\mathrm{E}_{0}=1.5 \times 10^{-6} \mathrm{~cm} / \mathrm{yr}$, one calculates the histogram shown in Fig. 4.

(2) Alternatively, the dust may be being supplied to the asteroidal belt by a few catastrophic collisions, therefore sporadically. The dust density today may be much higher than its time-average over the last few hundred million years ${ }^{27}$. If we assume one such collision taking place 20 million years ago, resulting in an erosion rate of $1 \times 10^{-6} \mathrm{~cm} / \mathrm{yr}$, preceded by an erosion rate of $0.25 \times 10^{-6} \mathrm{~cm} / \mathrm{yr}$, we get the histogram of Fig. 5. To illustrate the effect of changing parameters, if the collision took place 10 million years ago, and the corresponding erosion rates were $2 \times 10^{-6}$ after collision and $0.2 \times 10^{-6}$ before collision, we obtain the histogram of Fig. 6. If this dustproducing collision were also a source of meteorites, it would increase the number of meteorites in the few-million year age interval, thus providing even closer agreement with the data.

More accurate information on the radiation ages of a lange number of meteorites is necessary before it would be reasonable to calculate a more complicated and perhaps more physically significant erosion rate. It should be noted, however, that a time-decreasing enosion rate (which might correspond to a dust loss rate by PoyntingRobertson effect greater than a dust accretion rate) does not duplicate the shape of the radiation age spectrum.

In summarizing it is probably well to point out explicitly the role of space erosion in this model. Space erosion is not purported to be the sole agent regulating the observed radiation ages of the chondrites. Rather, it has two effects: (1) It is responsible for the cut-off in radiation age of $55 \times 10^{6}$ years, since the chondrites formed previous to this date are completely eroded away and never reach earth. (2) It shifts the measured age of chondrites to lower values than the true age, as per Eq. (5). This effect is itself a function of age. For example, a measured age of $50 \times 10^{6}$ years, with a value of $E=0.5610^{-6} \mathrm{~cm} / \mathrm{yr}$, implies a true radiation age of $78 \times 10^{6}$ years, while a measured age of $5 \times 10^{6}$ years gives a true age of only $5.1 \times 10^{6}$ years. Thus space erosion is an important effect only for the older meteorites, unless the actual erosion rate is much greater than that estimated here.

\section{The Bronzite Cluster}

It is apparent from Figs. 3-6 that a discrepancy between theory and experiment exists primarily in the low-age region of the spectrum, $0-5$ million years. The excess of observed values over those predicted by the model cannot be removed by any reasonable manipulation of the parameters. This leads naturally to the supposition that one particular collision occurred during this time interval, giving birth to a significant number of meteorites. Due to the recent date of this collision, its age is not affected by space erosion.

The data of Zahringer ${ }^{10}$ clearly indicates such a collision. Of 32 bronzite chondrites measured by him, about 24 have measured ages of about 4 million years, indicating that they were formed in one collision at this time. The few bronzites with higher ages (ranging up to about 20 million years) may be remnants from previous bronzite-producing collisions or may simply be examples of the errors involved in estimating cosmic radiation ages. 
If the bronzite age spectrum is subtracted from the total chondritic spectrum of Figs. 3-6, the agreement between the proposed model and the data is greatly enhanced. The bronzite cluster, then, fits into the model as a perturbation on the continuing background of chondriteproducing asteroidal collisions.

other age clusters tentatively pointed out by Anders ${ }^{7}$ and others seem to have been washed out by the accumulation of more data. At any rate, there does not seem to be enough evidence for their existence to justify any attempt to discuss them in terms of this model at the present time.

\section{$\frac{\text { Applicability of Previous Criticisms }}{\text { of Space Erosion }}$}

The effect of space erosion on the radiation ages of meteorites has been reviewed, critically evaluated, and finally discarded, chiefly by Anders 29 and Eberhardt and Geiss 17 . We review here the criticisms and their applicability to the present model:

(1) All stone meteorites should have the same age, given by $\mathrm{T}=(\mathrm{aE})^{-1}$. In the present model this conclusion does not follow, the distribution in ages being given instead by Eq. (13).

(2) There should be a one-to-one correlation between the age of a given meteorite and its hardness, e.g., a more friable meteorite crumbles more easily and would therefore erode more quickly and would therefore have a younger age, again given by $T=(a E)^{-1}$.. In the present model no such one-to-one correspondence should exist since, meteorites being produced continuously, a more friable meteorite might have been created at any time and might therefore show any radiation age from 0 to 55 million years. But consider the entire mass spectrum of meteorites created within one time interval: a langer number of the more friable will be completely eroded before capture by the earth than of the less friable. Then there should exist a trend between hardness of meteorites and their radiation ages; the harder meteorites should in general have longer radiation ages. At present there is not enough data to investigate this problem: the fact that one particular meteorite may be easily crushed and yet show a long radiation age, or vice versa, is not significant.

(3) The size distribution of meteorites ${ }^{1}$ : this criticism refers to a model in which all the stone meteorites were created at the time of creation of the irons, about $5 \times 10^{8}$ years ago. Then "one cannot expect that all stone meteorites started out some 15 meters in diameter and were worn down to 1-meter diameter before they dared to collide with the earth." But any meteorites that had collided with the earth early in their history would have done so some tens to hundreds of millions of years before earth-men began collecting them, and would certainly be lost to us. Therefore the criticism is not valid even for the model it attacks; it has no signifieance to the present model, which takes as one of its bases the observed mass distribution of Fig. 2.

(4) Is it reasonable that the stones actually are eroded faster than the irons $^{23}$ ? This was discussed in evaluating the applicability of Eq. (11). The faster erosion of stones does seem reasonable, but is certainly not proven. The erosion rate for irons should not be greater than $23.7 \times 10^{-8} \mathrm{~cm} / \mathrm{yr}$ in order to preserve the model; that is, about an order of magnitude less than the stone erosion rate. Experimental evidence is needed to decide this question finally.

\section{References}

1. Urey, H. C., Primary and secondary objects, J. Geophys. Research 64 1721-1737 (1959).

2. Opik, E. J., Collision probabilities with the planets and the distribution of interplanetary matter, Proc. Roy. Irish Acad., $54,165,1951$.

3. Arnold, J. R., The origin of meteorites as small bodies, 2 and 3, Ap. J., 141, $1536-1555,1964$.

4. Hapke, B. W., Optical properties of the moon's surface, Proc. Conf. on Nature of the Lunar Surface, Greenbelt, Maryland, April, $1965 a$.

5. Hapke, B. W., A comparison of the infrared spectra of the moon and simulated lunar surface materials, Ap. J., (to be published) $1965 \mathrm{~b}$.

6. Kuiper, G. P., Astron. J., 55, 164 (1950).

7. Anders, E., Meteorite ages, The Solar System, vol. 4, p. 402 edited by B. M. Middlehurst and G. P. Kuiper, University of Chicago Press, Chicago, 1963.

8. Goebel, K., and P. Schmidlin, Tritium Messungen an Steinmeteoriten, Z. Naturforsch, 15a, $79-82,1960$.

9. Heymann, D., Cosmogenic and Radiogenic Helium, Neon and Argon in Amphoteric Chondrites, J. Geophys. Res., 70, 3735-3744.

10. Zahringer, I., Chronology of chondrites with rare gas isotopes, Meteoritika, to be published, (1965).

11. Kirsten, T., Krankowsky, D., and J. Zahringer, Edelgas-und Kalium-Bestimmungen an einer grosseren Zahl von Steinmeteoriten, Geochim. et Cosmochim. Acta, 27, 13-42 (1963). 
12. Goebel, K., P. Schmidlin, and J. Zahringer, Z. Naturforsch, 14a, 996 (1959).

13. Geiss, J., H. Oeschger, and P. Signer, Radiation ages of chondrites,

Z. Naturforsch., 15a, 1016-1017, 1960.

14. Begemann, F., P. Eberhardt, and D. C. Hess, $\mathrm{He}^{3}-\mathrm{H}^{3}$-Strahlungsalter eines

Steinmeteoriten, Z. Naturforsch. 14a $500-503,1959$.

15. Stoenner, R. W., O. A. Schaeffer, and R. Davis, Jr., Meteorites as space probes for testing the constancy of cosmic radiation, J. Geophys. Res., $65,3025,1960$.

16. Fireman, E. L. and J. DeFelice, Argon-39 and tritium in meteorites, Geochim. et Cosmochim. Acta 18 183-192 (1960).

17. Eberhardt, P., and J. Geiss, Meteorite classes and radiation ages, Isotopic and Cosmic Chemistry, dedicated to Harold C. Urey; edited by H. Craig, S. L. Miller, and G. J. Wasserburg, pp. 452-470, North-Holland Publishing Company, Ansterdam, 1964.

18. Whipple, F. L., and E. L. Fireman, Calculation of erosion in space from the cosmic-ray exposure ages of meteorites, Nature 183, 1315, 1959.

19. Fisher, D. E., Space Erosion of the Grant Meteorite, J. Geophys. Res., 66, 1509-1511 (1961).

20. Brown, H., The density and mass distribution of meteoritic bodies in the neighborhood of the earth's orbit, Proc. First Internat. Space Sci. Symposium (NorthHolland Publ. Co. Amsterdam) 1063-1070 (1960).

21. van de Hulst, H. C., Zodical light in the solar corona, Ap. J., 105, 471 (1947).

22. Opik, E. J., Meteor impact on solid surfaces, Irish Astron. J., 5, 14 (1958).

23. Geiss, J. and H. Oeschger, The impact of cosmic radiation in meteorites, Proc. First Internat. Space Sci. Symposium (North-Holland Publ. Co. Amsterdam) p. 1071-1079 (1960).

24. Elsasser, H., Mitteilungen Astron. Inst. Univers. Tubingen, No. 35, 61 (1958).

25. Piotrowsky, S., The collisions of asteroids, Acta Astron., 5, 115, 1953.
26. Buddhue, J. D., Popular Astronomy, 50, 390 (1942).

27. Harwit, M., Origins of the zodical dust cloud, J. Geophys. Res., 68, 2171-2180 (1963).

28. Hintenberger, H., H. Konig, L. Schultz, and H. Wanke, Radiogene, spallogene und primordiale Edelgase in Steinmeteoriten, Z. Naturforsch., 19a, 327-341, 1964a.

29. Anders, E., Origin, age, and composition of meteorites, Space Sci. Re., 3, 583-714, 1964. 
Table 1.

Radiation ages of chondrites, in units of $10^{6}$ years. From measured $\mathrm{He}^{3} / \mathrm{H}^{3}$ and from $\mathrm{He}^{3}$ values taken with an averaged $\mathrm{H}^{3}$ value.

\begin{tabular}{|c|c|c|c|}
\hline deteonite & $\begin{array}{l}\text { Age, from } \\
\mathrm{He}^{3} / \mathrm{H}^{3} \\
\text { measured }\end{array}$ & Reference & $\begin{array}{l}\text { Age, from } \\
\mathrm{He}^{3} \text { and } \\
\text { average } \mathrm{H}^{3}\end{array}$ \\
\hline Ramsdorf & $\begin{array}{l}3.4 \\
1.6\end{array}$ & $\begin{array}{r}12 \\
8\end{array}$ & $3.2-4.1$ \\
\hline Elenovka & $\begin{array}{l}24 \\
13\end{array}$ & $\begin{array}{r}13 \\
8\end{array}$ & $15-20$ \\
\hline Breitscheid & 12 & 8 & 23.5 \\
\hline Abee & $\begin{array}{l}2.7 \\
8\end{array}$ & $\begin{array}{r}8 \\
14\end{array}$ & 6 \\
\hline Kunaschak & $\begin{array}{l}2.4 \\
1.5 \\
2.8\end{array}$ & $\begin{array}{r}8 \\
8 \\
13\end{array}$ & $2-3$ \\
\hline Bruderheim & 35 & 14 & 23 \\
\hline Murray & $15\left(\mathrm{Ar}^{39} / \mathrm{He}^{3}\right)$ & 15 & $2-3.5$ \\
\hline Richardton & $80\left(\mathrm{Ar}^{39} / \mathrm{Ar}^{38}\right)$ & 15 & 16 \\
\hline St. Michel & $110\left(\mathrm{Ar}^{39} / \mathrm{Ar}^{38}\right)$ & 16 & 16 \\
\hline
\end{tabular}




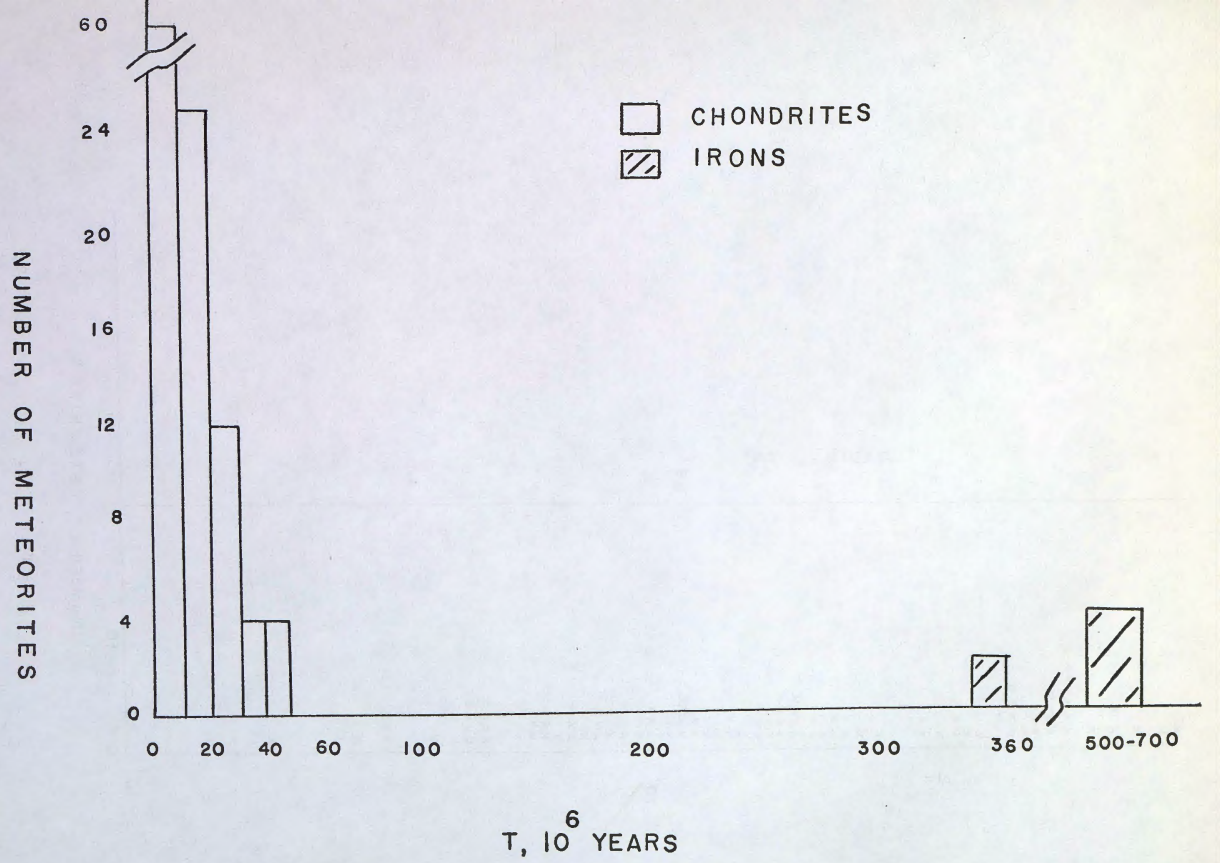




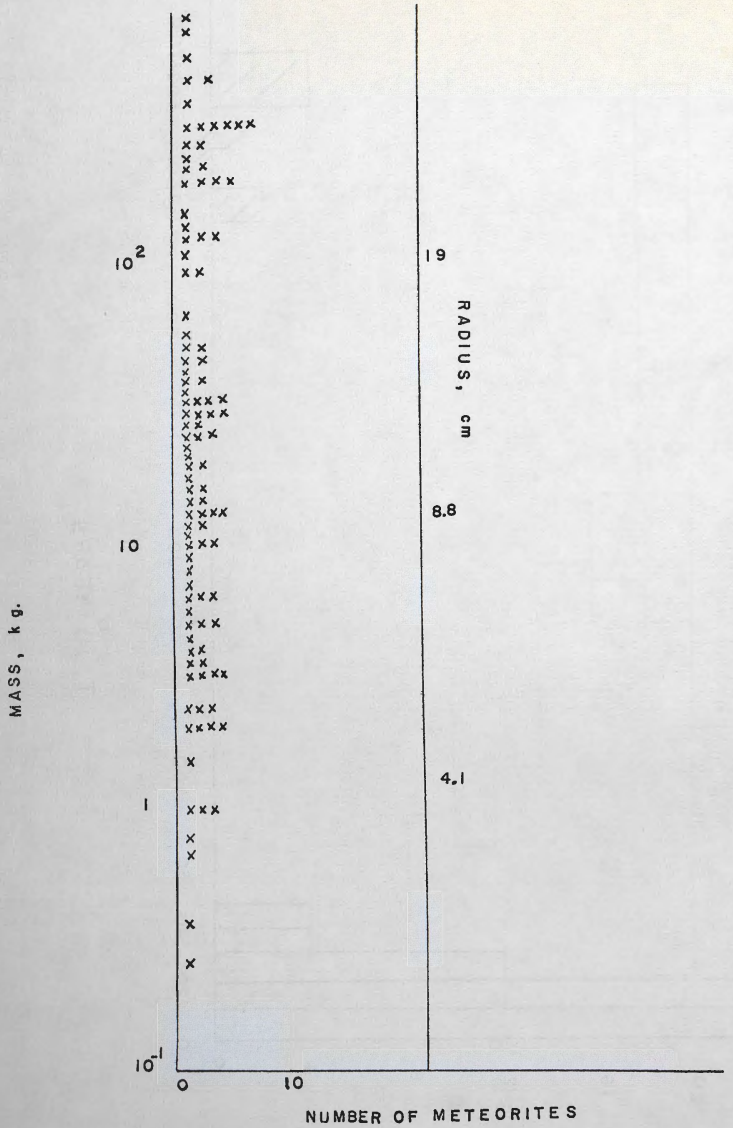

Figure 2. Mass distribution of chondrites with ages shown in Fig. 1. 


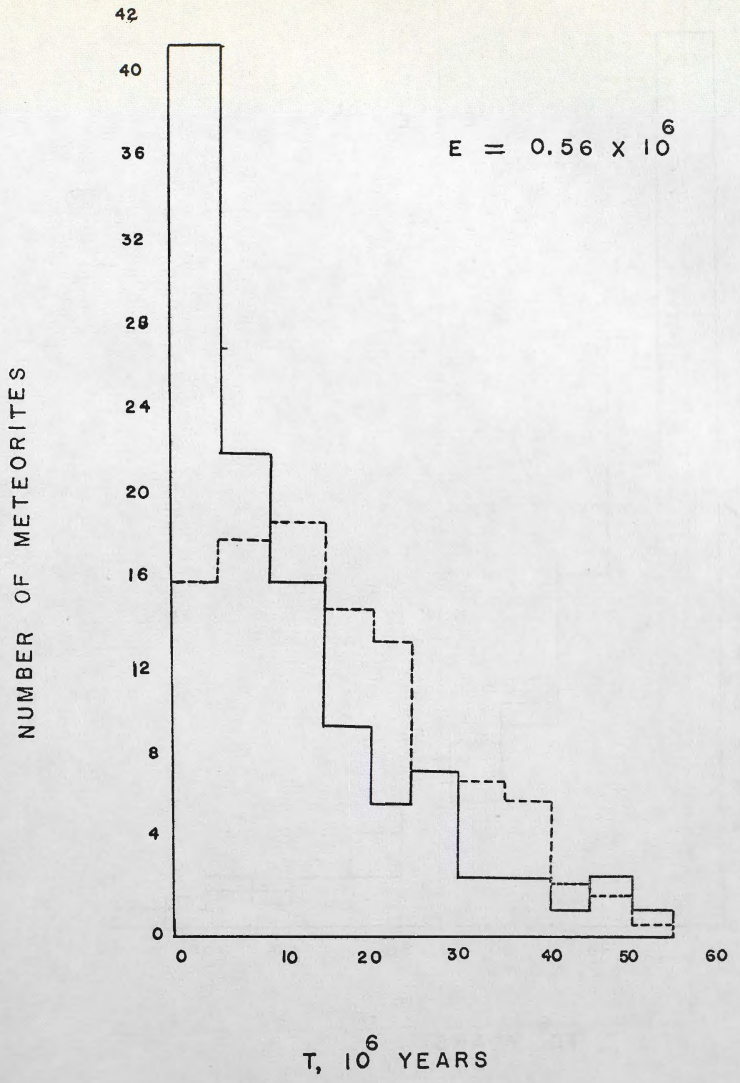

Figure 3. Calculated (dashed line) versus measured (solid line) radiation ages, for $\mathrm{E}=0.56 \times 10^{-6} \mathrm{~cm} / \mathrm{yr}$. 


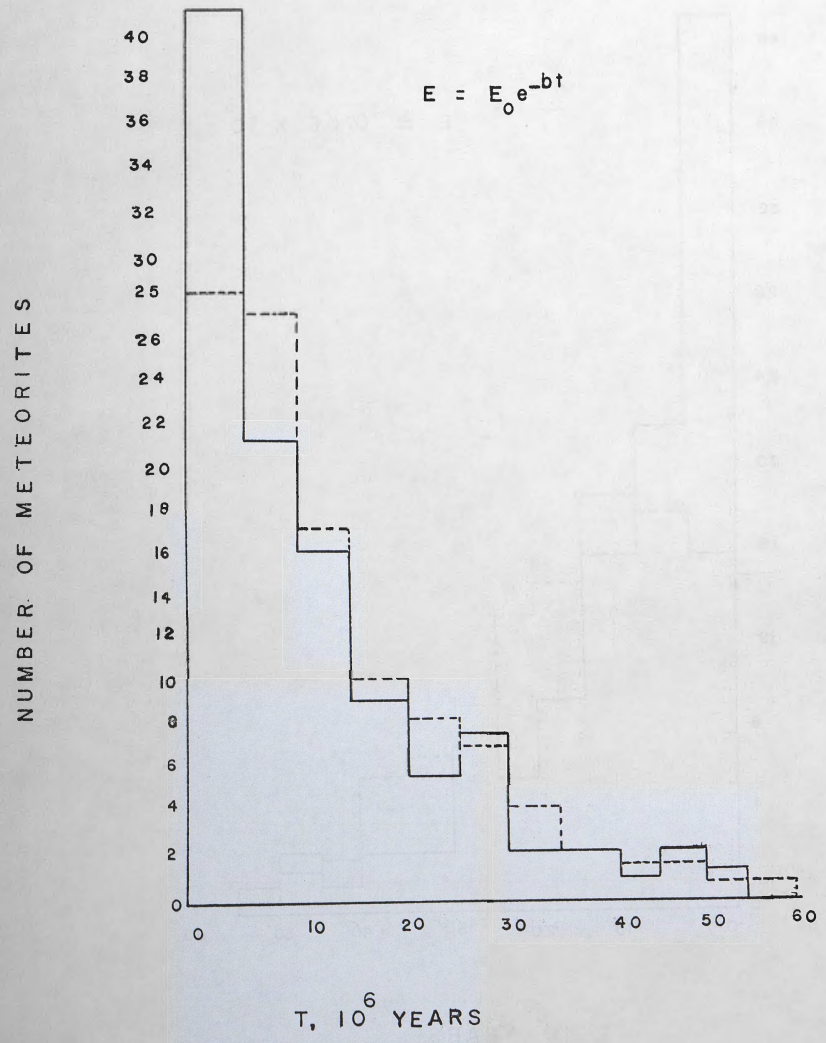

Figure 4. Calculated (dashed line) versus measured (solid line) radiation ages, for $\mathrm{E}=\mathrm{E}_{0}{ }^{-\mathrm{bt}}$. 


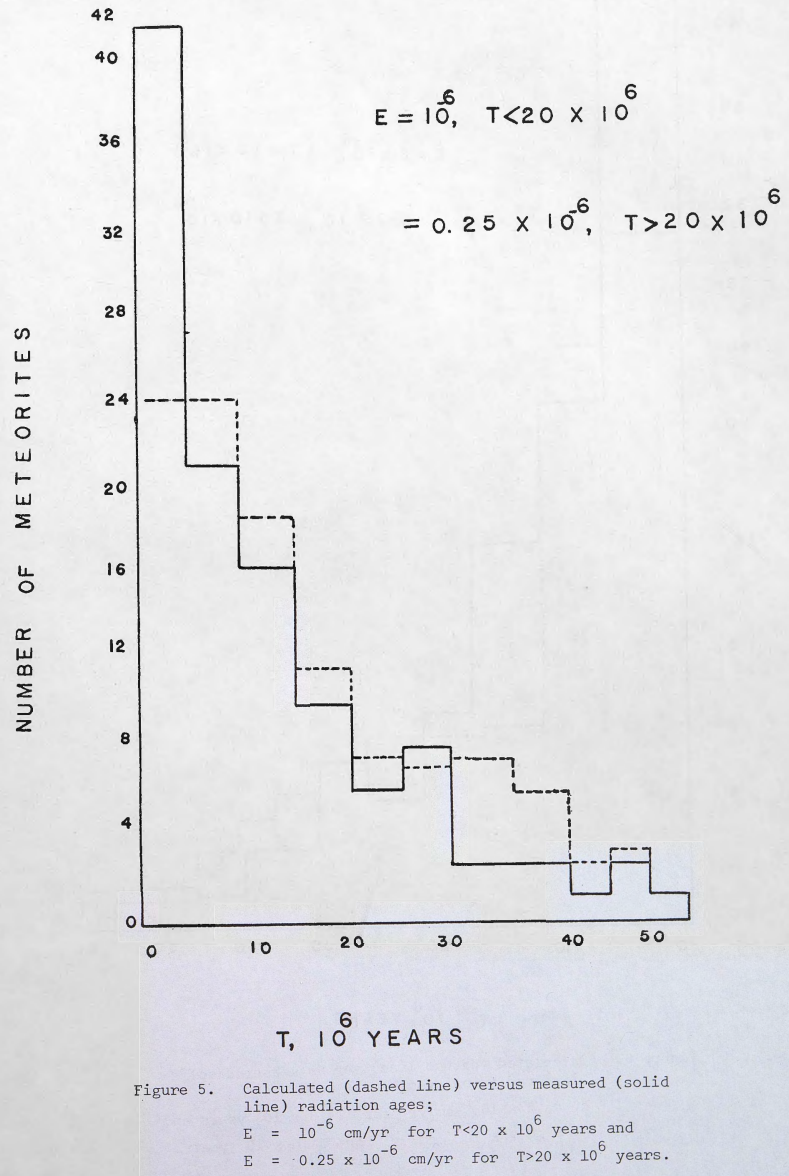




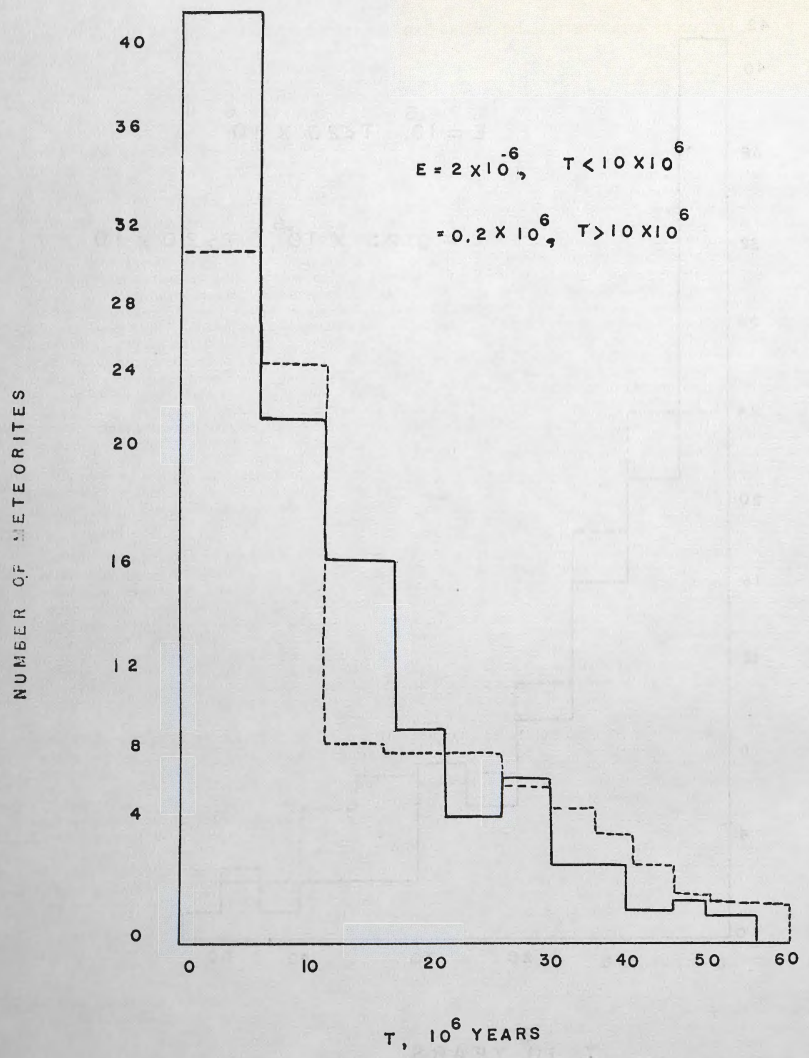

Figure 6. Calculated (dashed line) versus measured (solid line) radiation ages;
$E=2 \times 10^{-6} \mathrm{~cm} / \mathrm{yr}$ for $\mathrm{T}<10 \times 10^{6}$ years and
$E=0.2 \times 10^{-6} \mathrm{~cm} / \mathrm{yr}$ for $\mathrm{T} \geqslant 10 \times 10^{6}$ years. 